\title{
The Field of Emergence in the Aspects of Communicative Situation
}

\author{
Albekov NN ${ }^{*}$ \\ Chechen State University, 32 Sheripov st., Grozny, the Chechen Republic, Russia
}

${ }^{*}$ Corresponding author: Chechen State University, 32 Sheripov st., Grozny, the Chechen Republic, 364907, Russia,E-mail: alibecus@mail.ru

Citation: Albekov NN (2016) The Field of Emergence in the Aspects of Communicative Situation. J Neurol Neurol Disord 3(1): 102. doi: 10.15744/2454-4981.3.102

Received Date: March 09, 2016 Accepted Date: April 25, 2016 Published Date: April 29, 2016

\begin{abstract}
Communicative situation is a basis, which designates potential models of "constructed forms". It is within the field of emergence models of text, that can be potentially prognosticated in a certain communicative situation, are designated. Every text can be assumed as conceptual system structured on the base of certain communicative situation. However in the process of "structuring" of a certain model of "conceptual system" consciousness of a recipient is able act only within the border of the field of emergence for going out of this border indicates misunderstanding of the communicative situation.

Keywords: Field of emergence; Communicative situation; Verbalization; Vocabulary; Interioriztsia; Lexical unit; Model; Linguistic fuzzy sets; Potential; Structuring; Center; Emergence; Core
\end{abstract}

\section{Introduction}

The problem of analysis of a situation as a factor affecting the behavior of a person is widely studied. However, these studies tend to describe the causal phenomena in human behavioral psychology. In particular in the work by L. Ross and R. Nesbet who believe that in order to successfully predict the behavior of a particular person, we should be able to consider how he himself interprets this situation, understands it as a whole [1]. According to Karl Theodor Jaspers the situation is not only natural and logical, but rather semantic reality that realizes not as a physical, and a psychic, but as a concrete reality, which includes both of these factors - the reality that brings to my empirical being benefit or harm, which opens the possibility or supposes a border [2,3].

A number of linguistic works are also devoted to the analysis of speech units functioning in a particular communicative situation [4-6]. They mostly examine the aggregation of meaning of speech units, mainly of a verb, which may cover the whole conceptual network of thesaurus, depending on the communicative situation. J. Terken believes that communicative situation can be characterized in terms of at least three dimensions: the content, the speaker, and the communicative context [6]. As for definition of the communicative situation, it is presented as "a set of characteristics of the situational context, relevant (important) for the verbal behavior of participants of communicative situation, that influence on the choice of the speech strategies, techniques, and means" [7].

The subject of analysis of this work is a conception "the field of emergence" in a certain communicative situation, which has a number of characteristics that predict its use in the study of multi-dimensional structures. We interpret the conception "the field of emergence", as a unit of a language system, having polidirected universal structure, implying the existence of the core, the center and the periphery (Figure 1) [8]. Under the expression of "certain communicative situation" it is meant the linguistic and all kinds of personal and environmental extra-linguistic realities now and here that has a direct impact on the interpretation of this very communicative situation by an individual.

The research is an attempt to present a new conception "the field of emergence" in the aspects of a communicative situation, based on the field theory and synergy framework [9]. The uniqueness of the field of emergence when analyzing a communicative situation is in the fact that it prognosticates the full potential of probable variants of interpretations and verbalization of the communicative situation, instead of meaning of a single speech unit. We believe that the field of emergence is the most versatile unit when considering or analyzing the communicative situation as a whole, since it is within the field of emergence the models of text are designated, that potentially prognosticated by the communicative situation. The field of emergence covers multilevel means of functioning system of language: phonemic, word formation, lexical, phraseological, morphological, syntactic, stylistic, textual, interaction which causes an increment of meaning of the text, manifested as the result of all the processed actions. Multilevel of the field the emergence, along with of linguistic elements of the language system, is manifested in the presence of psychological, cultural, social and other extra-linguistic factors, which in complex combination form a field of emergence, on the basis of certain 
communicative situation. It should be stated that the field of emergence only prognosticates the potential models of the 'converted forms', applicable to this very communicative situation, for the text is a product of the communicative situation. Each text is different, and the problem faced by the interpreter in polidirected situations while structuring the model of a text is in designating of meaning matter, rooted in the communicative situation. The dimension of the of field emergence, i.e., the potential models that prognosticated within it are also depends on the particularity of the communicative situation.

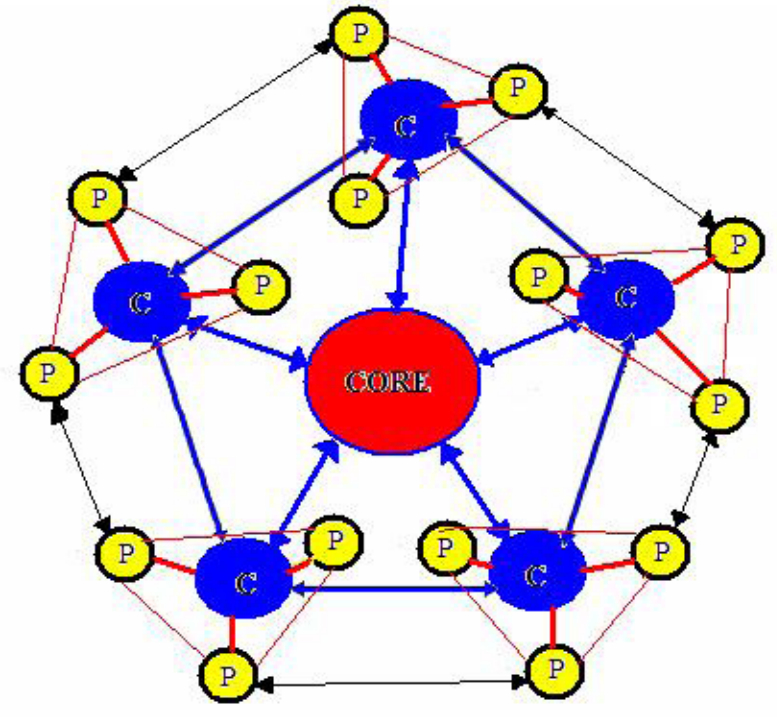

Figure 1: Model of field of emergence

The hugest field of emergence is caused by the communicative situation "supplication" addressed to God. For millions of people praying mainly can be in the same language, but the "supplication" of each of them is unique, applicable to a particular communicative situation. It is curious that the text of each of "supplication" is unique only in the aspect of communicative situation, while each of these texts comprises a) the same linguistic units, b) structured according to certain grammatical rules (syntax), c) structured according to certain functional and stylistic modifications. It is in the specificity of each of the versions of the text, prognosticated in the field of emergence; the property of the emergence of a particular text is manifested.

\section{Methods}

In order to reveal the potential of the field of emergence in a certain communicative situation we carried out an experiment in student groups of philological department of Chechen State University using, basically, the case method. The experiment was carried out in 2014 among the 6 groups in each of which there were 15 students (86 girls and 4 boys from 18 to 22 ages).

The task was that each participant, which acted as the applicant for the position of teacher of the Chechen language and literature at school, in the form of a monologue amount of three hundred words had to convince the director that he is the right specialist who is best suited for this job.

The goal of the experiment was by defining the communicative situation to "cause" the field of emergence and see: a) what are the syntactical, stylistic, cultural, mental peculiarities of the verbal variants of the interpretation of the communicative situation; b) The degree of manipulative capability of each variant according to parameters of analysis of the field of emergence [9]. c) Types of language resources. d) The quantity of vocabulary units. e) Ethno-linguistic specifics.

The results of the experiment showed that in the monologues the following groups of lexemes are mainly used: a) from 6 to $12 \%$ of complementary vocabulary, b) from 35 to $45 \%$ the vocabulary, indicating the personal moral and ethical qualities; c) from 55 to $65 \%$ lexicon with information about the professional qualifications and status; $\mathrm{g}$ ) from 1 to $3 \%$ greeting-farewell vocabulary.

From the presented ninety works in volume of 300 words (including prepositions and conjunctions) $95 \%$ of the work consists of $90-110$ vocabulary units. $4 \%$ of the work consists of $115-125$ vocabulary units and $1 \%$ of the work consists of $130-140$ vocabulary units.

In the process of intériorisation of communicative situation the recipient structures his own conceptual framework. Each of the work presented in this experiment is a proper conceptual system structured on the basis of predetermined communicative situation. However, in the process of "structuring" specific model "conceptual system" consciousness of the recipient can act only within the boundaries of the field of emergence, as going out of the field of emergence means misunderstanding of the communicative situation. No distortion, but misunderstanding. On the basis of the field of emergence unique geneses of increment of meaning is witnessed in which synergizing of information model of a speech generated by using invariant units of the language system, which, in turn, results the verbalization of communicative situation. 
In the structure of the field of emergence of each of the carried out works there is) absolutely identical core, i.e., each work is a modification that composed on the basis of the communicative situation - assurance of competence; b) Each of the works has similar centers in the three postulates verbalized in the form of simple sentences I am an expert, I love children, I want to work in the school; c) the originality to each of the work gives the linguistic fuzzy sets the maximum number of which at the level of lexis are 148 units. The emergence of each of the variants is manifested in peculiarity of the syntactical structuring of fuzzy linguistic units, style of presentation, intonation and extra linguistic factors, accompanying the communicative situation. Emergent properties are caused as a result of synergizing language resources on the basis of invariant patterns of the language system in the process of constructing the essential whole, i.e., text [1.2.3.].

In the context of the emergence of the text it is interesting the manipulative potential of each of the versions of the text. In the papers submitted by students, there is a high degree of use of complementary vocabulary. However, the degree of manipulability of the text does not depend on the amount of use of that vocabulary. Moreover, the degree of manipulability also does not depend on the volume of the whole text (lexical units). In the most of texts there is repetition of the same lexical units, excessive repetition of which brings a certain lack of vocabulary and emotional redundancy of the text at the same time, thereby reducing its manipulative potential. The text, in which maximum number of lexical units is used (148), has a high degree of manipulability, but you can not say that this is the most effective text. It can be attributed to the category of those texts in which the theme-ordering is structured properly. As for style, there guessed so-called "A-student syndrome", in whose speech, as a rule, there is a restrained vocabulary of emotional coloring. The content of the text, is focused at the presentation of own competence, there prevail sentences describing the dignity of the addresser, his ideas, notes that gives to the text an official tone. There is a slight deviation from the "live" speech.

The work that, according to our theory of emergence, has the highest possible manipulability consists of 129 lexical units [9]. However, here, from the very start after words of welcome, "I see - you still have a passion for flowers" it is achieved communicative intimacy with attention of the subject of dear passion of the addressee, though not directly related to the goal. Presentation of the purpose of visit begins with important arguments for the school tasks such as compulsory exam on Chechen language adopted recently. Short and pretty meaningfully said about the respective areas of competence and experience. The desire to work in this school is due to belonging to a dynasty (using such significant words as: grandfather, father, uncle). At the end of speech complementary vocabulary is used, in which the high school rating is argued due to skilful and successful leadership. Vocabulary, more enjoyable and memorable to the addressee is used at the end of the text.

In a communicative act choice of a functional and stylistically differentiated model of communication is often prognosticated by the communicative situation [7]. It should be noted that the emotional component here is one of the most important indicators in determining communicative situation, as it is considered that the situations themselves are interpreted and stored in memory on the basis of their distribution, especially for emotional categories: "pleasant", "formal" or "dangerous" [10,11]. Characteristic peculiarities of emotionally colored communicative situation allow determine it as a code, on the basis of which it is possible to predict the synergistic processing of the communicative model. Emotionally colored communicative situation directs the choice of various linguistic fuzzy sets, which, in turn, exist in the system as a means of constructing.

\section{Results}

The foregoing leads to believe that on the basis of every communicative situation the field of emergence is witnessed, within which, depending on the communicative situation, there can be prognosticated: a) identical core; b) semantically similar center; c) phonetic, syntactic, lexical and stylistic originality at the level of linguistic fuzzy sets.

The most important property, of the field of emergence is that on its base there can be estimated an approximate amount of linguistic fuzzy sets of a certain communicative situation.

The originality of each outgoing text from a certain addressee is psychologically uniqueness of each individual; his perceptions of the present reality, constructing or verbalizing own particular interpretation of the communicative situation. However, each of the presented variants of verbalization does not go out of the boundaries of the field of emergence, caused on the base of this very communicative situation [12].

\section{Conclusions}

The results of carried out research (including the said experiment) allow to make the following conclusions: a) the of field emergence is caused in every communicative situations; b) within the field of emergence there can be prognosticated models of text, verbalizing the communicative situation; c) the number of linguistic fuzzy sets that define the originality of the text is limited due to certain phonetic variants, structural forms, syntactic constructions, functional and stylistic models, lexical units and vocabulary appropriate to the communicative situation; g) originality of text, as a result of verbalization of the communicative situation, is achieved by the potential of linguistic fuzzy sets.

\section{References}

1. Ross L, Nisbett RE (1992) The Person and the Situation. 
2. Jaspers K (1956) Philosophie Bd II. Berlin-Goettingen-Heidelberg.

3. Bates E, Elman J, Johnson M, Karmiloff-Smith A, Parisi D, et al. (1998) Innateness and emergentism. In Bechtel W, Graham G, ed, A comparison to cognitive sciences. Oxford: Basil Blackwell.

4. Gorbunova LI (2010) The cognitive image of the situation as a basis of the semantic structure of a language unit. Irkutsk 361.

5. Grady W (2008) Emergentism.

6. Terken J (2001) Variability and speaking styles in speech synthesis. In Keller E, Bailly G, Monaghan A, Terken J, Huckvale M, eds, Improvement Speech Synthesis. Chichester, UK: John Wiley Sons 199-203.

7. Zherebilo TV (2007) Lingua - Stylistic paradigm in informational area of modern linguistics. Nazran: Pilgrim 192.

8. Albekov NN, Zherebilo TV (2015) Field emergence as a unit of the language system. Fundamental Res 2.

9. Albekov NN (2015) Emergence in the aspects of field theory. Modern Problems Science Edu № 2.

10. Kustova GI (2014) Types of derivative meanings and mechanisms of their expansion. M. Izd. Yaziky slavanskoi kultury 470.

11. Prokhorov UE, Sternin IA (2007) Russian communicative field.

12. Albekov NN (2009) Emergence as a component of invariantno-variativnoy structure of the translated texts. Avtoreferat, Stavropol 23.

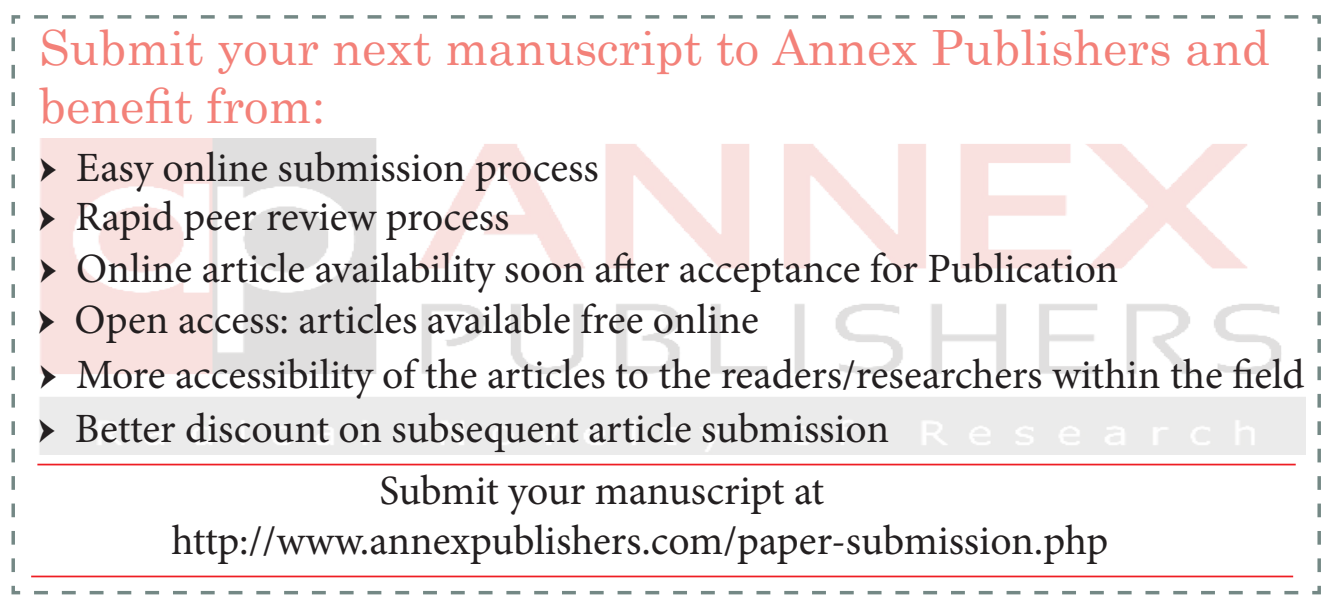

